\title{
Prevalence and Genotypic Characterization of HBV in HIV-Infected Patients from Kwazulu-Natal, South Africa
}

Lorato Mosetsanagape Modise ( $\sim$ madyibilorato@yahoo.com )

North-West University https://orcid.org/0000-0001-7008-157X

Nomathamsanqa Patricia Sithebe

North-West University

\section{Research}

Keywords: Hepatitis B virus, HBV/HIV co-infection, HBV genotype, drug resistance

Posted Date: April 2nd, 2020

DOI: https://doi.org/10.21203/rs.3.rs-20564/v1

License: (c) (1) This work is licensed under a Creative Commons Attribution 4.0 International License.

Read Full License 


\title{
PREVALENCE AND GENOTYPIC CHARACTERIZATION OF HBV IN HIV- INFECTED PATIENTS FROM KWAZULU-NATAL, SOUTH AFRICA
}

\section{Authors Names}

Lorato Mosetsanagape Modise and Nomathamsanqa Patricia Sithebe

\section{Authors contact details}

Lorato Mosetsanagape Modise: madyibilorato@yahoo.com, virology laboratory, department of Microbiology, Faculty of Agriculture, Science and Technology, North-West University, Mafikeng Campus, Private Bag X2046, Mmabatho 2735, South Africa.

Nomathamsanqa Patricia Sithebe: pnsithebe@gmail.com, virology laboratory, department of Microbiology, Faculty of Agriculture, Science and Technology, North-West University, Mafikeng Campus, Private Bag X2046, Mmabatho 2735, South Africa.

Correspondence: madyibilorato@yahoo.com; Virology Laboratory, Department of Microbiology, Faculty of Agriculture, Science and Technology, North-West University, Mafikeng Campus, Private Bag X2046, Mmabatho 2735, South Africa.

\begin{abstract}
Introduction: The co-infection of HIV with HBV is very common due to shared mode of transmission. HBV/HIV co-infection impact on low HBeAg expression, high HBV replication, causes progressive liver disease, cirrhosis, liver cancer and high mortality. Coinfection may lead to cross-resistance of HBV and HIV drugs due to drug-related immune therapeutic pressure or hepatotoxicity. These challenges necessitate continuous surveillance for HBV among HIV infected individuals to aid patient treatment management. Hence we
\end{abstract}


conducted this study to characterise HBV among HIV infected patients in Durban, KwaZuluNatal of South Africa.

Methods: Serum was screened for HBsAg using ELISA, followed by DNA extraction from all samples. Genotyping of HBV was done through PCR amplification, Sanger sequencing and phylogenetic analysis.

Results: Of the 50 samples in this study $100 \%(\mathrm{n}=50 / 50)$ were HBsAg positive. HBV/HIV coinfection was 78\% (n=41/50) based on PCR amplification of the HBV partial surface gene and 92\% ( $\mathrm{n}=38 / 41)$ of the amplicons were successfully sequenced. Phylogenetic and sequence analyses identified patients nucleotide sequence as Genotype A. Mutations prevalence in the HBsAg region was $47 \%(n=18 / 38)$; including mutations associated with diagnostic failure (K122R and T143S) and 7 vaccines escape mutations (P127T, G145R, S207N, Y200T, E164D, Y206H and L209V). Prevalence of mutations associated with drug resistance was 57\% $(n=8 / 14)$ within the reverse transcriptase region. Drug resistance mutations included lamivudine resistance at $71 \%(\mathrm{n}=5 / 7)$, telbivudine resistance at $57 \%$

$(n=4 / 7), 14 \%(n=1 / 7)$ for entecavir resistance and $43 \%(n=3 / 7)$ for adefovir resistance. Mutations causing resistance to lamivudine and telbivudine were M204V, L180M, V163I, and S202K; with S202K also causing resistance to entecavir and adefovir resistance mutation were I253Y, I223V and M250I. The drug susceptibility prevalence was 68\% ( $\mathrm{n}=26 / 38)$. Multiple drug resistance mutations within a single sample contained L180M, M204V, S202K and M250I mutations.

Conclusion: This study shows the predominance of HBV genotype A in HIV-infected patients and the HBV mutations present in HBV/HIV co-infected individuals. HBV mutations associated with drug resistance suggest the need for continuous HBV screening and use of tenofovir ART regimen among HBV/HIV co-infected individuals. 
Keywords: Hepatitis B virus, HBV/HIV co-infection, HBV genotype, drug resistance

\section{Introduction}

Hepatitis B virus (HBV) is an enveloped virus a prototype of the Hepadnaviridae family and the Orthohepadnavirus genus is important human pathogens [1]. HBV is estimated to infect more than 300 million people globally and cause of liver disease and liver cancer with approximately 1 million deaths from chronic liver disease and hepatocellular carcinoma (HCC) per year [2]. According to the Baltimore virus classification HBV belongs to the Class VII viruses, it contains a partly inimical relaxed and circular (RC-dsDNA) double stranded DNA genome consisting of 3200 nucleotide base pairs, it replicate via a ssRNA intermediate $[3]$. 
Hepatitis B virus infects cells in the hepatocytes causing liver infection, which may clinical manifest into symptomatic or asymptomatic acute hepatitis characterized by inflammation of liver to fulminant hepatitis. Failure to treat acute HBV hepatitis may proceed to chronic HBV hepatitis which can lead to cirrhosis and HCC [4]. To diagnose HBV infection, disease associated with HBV and to distinguish acute and chronic infections numerous tests such as clinical, biochemical, serology and molecular techniques are conducted. The serological testing diagnose HBV by determining the HBV antibodies and antigens such as antigen (HBsAg); antibody to hepatitis surface antigen (anti-HBs), antibody to hepatitis B core antigen (anti-HBc) and IgM antibody subclass of anti-HBc (IgM anti-HBc).

HBsAg presence may be detected approximately 2 weeks of exposure and is the main clinical marker indicating acute or chronic infection and prevalence as well as endemicity of HBV infection. Molecular techniques diagnose HBV by determining the qualitative and quantitative HBV-DNA. HBV genomes have been classified into ten major genotypes designating A to $\mathbf{J}$ based on the whole genome genetic heterogeneity of about $8 \%$ [5]. The genetic heterogeneity results from the lack of proofreading mechanism of the viral polymerase during viral DNA replication [6]. HBV sequence heterogeneity is also caused internally by selective immune system pressure and externally by vaccination and antiviral treatment. However, the different HBV genotype distributions differ geographically and that has an impact on the HBV pathogenicity and treatment management. The co-infection of HIV with HBV is very common due to shared mode of blood-born transmission [7].

The common routes of transmission vary geographically depending on the endemicity of HBV. HBV and HIV treatment involves the use of lamivudine (3TC) [8]. However, HIV- infected individuals should not receive 3TC or emtricitabine (FTC) monotherapy for HBV infection because of development of drug resistance with 4 years of single-drug treatment [9]. Resistance 
to 3TC is characterized by the development of mutation rtm 204 (YMDD mutation). The 3TC should be used only for patients on fully suppressive ART, this mutation causes rapid uncontrolled HBV DNA replication and that increased death rates associated with HBV infection/disease.

Several studies have reported HBV prevalence among HIV-infected individuals from Durban in KwaZulu-Natal. However, most studies have focused on the sero-prevalence and studies focusing on the HBV genotype, HBV vaccine escape and drug-resistance are still limited in this area. Hence we conducted this study to determine the prevalence and genotypic characteristics of HBV among HIV-infected individuals in Durban.

\section{Methods}

\section{Study population and ethical clearance}

This was a cross-sectional study and a total of 50 stored frozen sera samples from HIVinfected individuals in Durban, KwaZulu-Natal cohort were used. The fifty participants were both male and females and they were recruited during the national health laboratory services (NHLS) screening programme in Durban. All participants were given informed consent and samples were collected and confirmed to be HIV-positive from previous serological tests. The patients were not on ART at that time. 


\section{Samples collection processing}

A total of 50 stored frozen serum samples from HIV-infected individuals in Durban were donated from NHLS and travelled on ice to the Virology laboratory at the North-West University. Upon arrival the samples were aliquoted into numerous $1.5 \mathrm{ml}$ Eppendorf tubes and stored at $-80{ }^{\circ} \mathrm{C}$ until further use.

\section{Hepatitis B Surface Antigen (HBsAg) Assay}

Briefly, $100 \mu 1$ of undiluted serum samples were used to detect presence of HBsAg using Monolisa HBsAg ULTRA confirmatory kit following the manufacturer instructions (BioRad, Raymond Poincare, Marnes-la-Coquette, France). This was performed using neutralization by excess of antibodies to anti-HBs (anti-HBs diluent: neutralization reagent) of the HBsAg found in specimens. The presence or absence of HBsAg in the specimens was determined by comparing the rate of fluorescent formation by the test specimens. The O.D. index of specimens was measured at $450 \mathrm{~nm}$ and compared to an O.D. cut-off rate mean index calibrator of a negative control HBsAg rate. Samples with an index greater or equal to the cut off rate were considered reactive for HBsAg.

\section{DNA Extraction of $\mathrm{HBV}$}

Serum obtained from patients was used to extract HBV DNA using QIAamp DNA Mini kit (Qiagen, Hilden, Germany) following the manufacturer's instructions. This technique allows the purification of total DNA from contaminants, inhibitors and nucleases from the serum. An aliquot of $200 \mu \mathrm{l}$ of the serum sample was added into $1.5 \mathrm{ml}$ Eppendorf tubes, to which $20 \mu 1$ of proteinase $\mathrm{K}$ and $200 \mu \mathrm{l}$ Buffer AL (binding buffer mixed with poly [A] carrier RNA) was added. The mixture was pulse-vortexed for 15 seconds to homogenise the mixture followed by 10 minutes incubation at $56^{\circ} \mathrm{C}$. The mixture was then transferred to a QIAamp spin column and centrifuged for 1 minute at $8000 \mathrm{rpm}$. The column was placed into a clean collection tube 
then $500 \mu \mathrm{l}$ buffer AW1 was added and centrifuged for 1 minute at $8000 \mathrm{rpm}$. The solution was aspirated, $500 \mu \mathrm{l}$ buffer AW2 was added followed by centrifugation for 3 minutes at 14 $000 \mathrm{rpm}$. The QIAamp spin column was placed in a sterile $1.5 \mathrm{ml}$ Eppendorf tube, $50 \mu \mathrm{l}$ of elution buffer (provided by the kit as buffer AE) was added directly into the column and incubated at room temperature for 5 minutes. The DNA was eluted by centrifugation at 8000 rpm for 1 minute and stored at $-20{ }^{\circ} \mathrm{C}$ until further analyses were performed. The negative control consisting of nuclease free water was included in the extraction procedure to identify contamination.

\section{PCR Amplification Assay- HBV}

\section{First Round and Nested-PCR}

A nested PCR amplification of the overlapping surface/ polymerase gene covering nucleotides 256 to 796 from EcoRI site as described previously [10]. Outer sense strand primer, S1 (5'CCT GCT GGT GGC TCC AGT TC-3’), and antisense strand primer, S2Na (5’-CCA CAA TTC KTTGAC ATA CTT TCC A-3’) were used. For each sample the

following reagent volumes and concentration were prepared: $18.5 \mu 1$ nuclease free water, 2.5 $\mu 1$ 10x PCR buffer with $\mathrm{MgCl}_{2}, 0.5 \mu 110 \mathrm{mM}$ dNTP mix, $0.5 \mu \mathrm{l}(50 \mathrm{uM}$ ) forward primer $\mathrm{S} 1$; $0.5 \mu 1(50 \mathrm{uM})$ reverse primer S2Na anti-sense primer, $0.125 \mathrm{Taq}$ DNA polymerase. A total of $22.5 \mu \mathrm{l}$ of master mix was aliquoted into a $0.5 \mathrm{ml}$ thin-walled PCR tube and $3 \mu \mathrm{l}$ of DNA template was added. The PCR reaction mixtures $(25.5 \mu 1)$ was subjected to amplification of HBV DNA, carried out in an automated touch down thermal cycler CFX96 (Bio-Rad, Raymond Poincare, Marnes-la-Coquette, France). The HBV DNA amplification conditions were 40 cycles involving denaturation at $95{ }^{\circ} \mathrm{C}$ for 4 minutes, annealing at $55{ }^{\circ} \mathrm{C}$ for 45 seconds, elongation at $72{ }^{\circ} \mathrm{C}$ for 1 minute, and final extension at $72{ }^{\circ} \mathrm{C}$ for 10 minutes. First round PCR product was used as a template for nested PCR. An aliquot of $3 \mu 1$ of the first round PCR 
reaction was subjected to a nested PCR, the master mix volume and concentration were prepared as same for the first round PCR. The nested PCR conditions used were the same as first round PCR protocol. Forward primers S6E (5'-GAGAAT TCCGAGGACTGG GGA CCC TG-3) and reverse primer S7B (5’-CGG GAT CCT TAG GGT TTA AAT GTATAC C-3') were used during nested PCR. 'The negative control consisting of nuclease free water and a positive control were included in the PCR amplification assays.

\section{PCR products verification}

PCR products were qualitatively verified using $1 \%$ agarose gel (ThermoFischer,Waltham, Massachusetts) stained with $0.15 \mathrm{U} / \mu$ l ethidium bromide (Biorad, California, USA). Aliquot of $10 \mu 1$ PCR product was mixed with $2 \mu 1$ 10x loading buffer. The mixtures were run on $1 \%$ gel along with a molecular weight maker (based on the viral gene of interest) as a band size reference. The agarose gel was run at $100 \mathrm{~V}$ for 45 minutes. Gel was placed inside the UV transilluminator to visualise and image capturing.

\section{Sequencing}

The PCR products were sent for direct sequencing at the Inqaba Biotechnological Industry, PTY, LTD, Pretoria, South Africa. The amplicons were prepared for direct sequencing using the BigDye Terminator v3.0 Cycle Sequencing Ready Reaction Kit (Applied Biosystems., Foster City, USA) and sequencing was done using the ABI 3130XL Genetic analyser (Applied Biosystems, Foster City, CA).

\section{Sequencing reaction}

Sequencing reaction mix for each sample was prepared as follows: $1.5 \mu 15 \mathrm{X}$ sequencing buffer, $1.0 \mu 1$ BigDye terminator, $1.0 \mu 1$ primer $(5 \mathrm{pmol} / \mu \mathrm{l}), 2.0 \mu 1$ template DNA, DEPCtreated water and primer sequences. A total of $10 \mu 1$ mixture was added into 96-well plate and subjected into sequencing under the cycling condition of 40 cycles involving denaturation at $94{ }^{\circ} \mathrm{C}$ for 1 
minute, annealing at $50{ }^{\circ} \mathrm{C}$ for 5 seconds, elongation at $60{ }^{\circ} \mathrm{C}$ for 1 minute, and final extension at $60{ }^{\circ} \mathrm{C}$ for 1 minute.

\section{Sequence reaction clean-up}

An aliquot of $50 \mu \mathrm{l}$ of the 1:1 ratio of sodium acetate: ethanol (NaAc:EtOH) was added into samples and centrifuged at $2000 \mathrm{~g}$ for 30 minutes. The well plates were inverted and centrifuged at $150 \mathrm{~g}$ for 1 minute. Pre-chilled $70 \%$ ethanol was added into the wells, and then centrifuged at $2000 \mathrm{~g}$ for 5 minutes. The samples were dried at $65{ }^{\circ} \mathrm{C}$ for 5 minutes and loaded into the sequencing machine ABI 3130XL Genetic analyser (Applied Biosystems, Foster City, CA). An aliquot of $10 \mu \mathrm{l}$ of the Hi-Di formamide was added into the sample for 5 minutes and loaded into a sequencing machine.

\section{Sequences analysis}

Nucleotide sequences of HIV and HBV were edited and contiguous sequences were formed using sequencher v4.5 (Gene Codes Coorporation, USA). The chromatograms were edited by removing unwanted and mixed nucleotides character we removed spaces within in the sequences. The contiguous sequences were formed by joining overlapping DNA sequences of a gene. The consensus sequences were compared with complementary genotype sequences from the GenBank using Basic local alignment search tool (BLAST). Representative sequences belonging to distinct genotypes were redeemed from the GenBank to make comparison with study sequences. Multiple sequence alignment of the sequenced nucleotides region was performed with CLUSTALW within the MEGA software package version 7.0.; the aligned nucleotide base sequences were subjected into phylogeny inference on MEGA 7.0. The neighbour-joining method was used to generate dendograms and the evolutionary relationship was performed using pairwise genetic distance with 1000 bootstraps replicate [11-13]. 
Frequency estimates of evolutionary divergence between nucleotide sequences were then estimated using the Kimura 2-parameter model [14].

\section{Results}

\section{Serology and PCR amplification}

The HBsAg was positive in 50/50 patients resulting in a 100\% HBV sero-prevalence. Of the $50 \mathrm{HBsAg}$ positive patients, HBV DNA was amplified in $78 \%(\mathrm{n}=41 / 50)$ of the $\mathrm{HBsAg}$ positive samples. HBV overlapping surface/polymerase region amplicons are shown as 547 bp bands below (Figure 1). PCR amplification could not be obtained for the other 11 (22\%) samples.

\section{Sequence Analyses of overlapping Surface/ Polymerase Gene Region}

Sequencing of the overlapping surface/polymerase gene region was successful in 38 out of 41 HBV-DNA positive samples. Phylogenetic tree analysis revealed the prevalent genotype A. Genotype A was identified in 92\% ( $\mathrm{n}=38 / 41)$ individuals nucleotide sequences. Figure 2 shows the phylogenetic relationship of the HBV nucleotide sequences. Sequences clustered with genotype A sequences previously deposited in GenBank. The genotype and subgenotypes of sequences were confirmed by depositing all the surface gene nucleotides sequenced into the Genotype2pheno database. The 38 individuals sequence were identified as genotype A and subgenotype A1 based on the results retrieved from the Geno2Pheno database with the percentage of similarity to sub-genotype profile of $96.85 \%-99.0 \%$.

\section{Amino acids mutations within HBsAg}

Mutations within the HBsAg of the overlapping surface/polymerase gene were determined from the 38 sequences, 47\% (18/38) amino acid variations were detected within the HBsAg region in at least 6 samples. Prevalent mutations were found in the "a" epitope, " $\beta$ "-cell epitope, " $\beta$ "-cell epitope and outside the "a" epitope as shown in (Table 1). The most common mutation 
was S207N at $71 \%(27 / 38)$, followed by L216V and A194V at 23\%, P70H at $21 \% \mathrm{~L} 209 \mathrm{~V}$ at 18\%, P217L at 8\%, F134L, E164D and T189I at 5\% and S204R, S117N, T143S, G145R, Y206H, P127T, Y200T, F129T and K122R all at 3\% (Table 1). 
Table 1 Amino acids mutations within the HBsAg region

$\begin{aligned} & \text { Amino acid } \\ & \text { variation }\end{aligned}$
Frequency (\%)

\begin{tabular}{|c|c|c|c|}
\hline \multicolumn{4}{|l|}{ "6"a" epitope } \\
\hline & K122R & 3 & Sub-serotype change $(\mathrm{d} / \mathrm{y})$ \\
\hline & F134L & 5 & Unclear \\
\hline & S117N & 3 & Unclear \\
\hline & T143S & 3 & Reflect the genotype variations \\
\hline \multicolumn{4}{|l|}{ 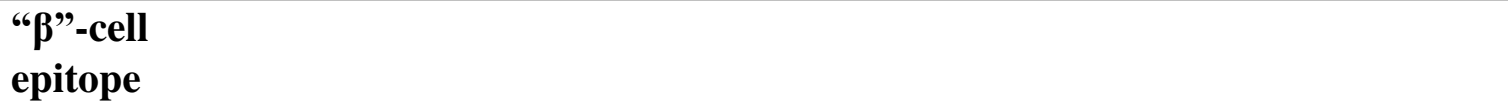 } \\
\hline & S207N & 71 & Unknown in genotype $\mathrm{A}$ \\
\hline & Y200T & 3 & Unknown in genotype A \\
\hline & G145A & 3 & Vaccine-escape mutant \\
\hline \multirow{2}{*}{$\begin{array}{l}\text { T-helper } \\
\text { epitope }\end{array}$} & \multirow[t]{2}{*}{$\mathrm{P} 127 \mathrm{~T}$} & \multirow[t]{2}{*}{3} & Vaccine-escape mutation \\
\hline & & & Lower reactivity in HBsAg assay \\
\hline $\begin{array}{l}\text { outside the "a" } \\
\text { epitope }\end{array}$ & E164D & 5 & Vaccine-escape mutation \\
\hline
\end{tabular}

Cause V173L mutation in the overlapping pol gene

$\begin{array}{lll}\text { L209V } & 18 & \\ \text { Y206H } & 3 & \\ \text { L216 } & 23 & \\ \text { A194V } & 23 & \text { Overt HBV infections } \\ \text { P70H } & 21 & \\ \text { P217L } & 8 & \\ \text { T189I } & 5 & \\ \text { S204R } & 3 & \\ \text { F129T } & 3 & \end{array}$




\section{Amino acids mutations within Polymerase region}

Mutations were determined within the polymerase region of $\mathrm{HBV}$ and the amino acid substitutions were identified at $36 \%(14 / 38)$ in different positions within the reverse transcriptase (RT) region. The M129L mutation was the most common in this study, accounting for $84 \%$ (32/38), followed by V163I at $78 \%$; I253Y at $50 \%$ and S105T at $40 \%$.

Other amino acid variations identified included L217R, A233S, Q125E, T128A, V214A, V204I, M204V, L180M, V173L and S202K at 21\%, 16\%, 13\%, 8\% and 3\% (Table 2).

The prevalence of mutations associated with drug resistance was 57\% (8/14) within the RT region (Table 3). Drug resistance mutations included lamivudine (LMV) resistance at $71 \%$ (5/7), telbivudine (LdT) at 57\% (4/7), 14\% for entecavir (ETV) and $43 \%$ for adefovir (ADV) resistance. Mutations causing resistance to LMV and LdT were M204V, L180M, V163I, and S202K. S202K mutation also causes resistance to ETV. ADV resistance mutations were I253Y, I223V and M250I (Table 3). Multiple drug resistance mutations within a single sample were identified from one sample containing L180M, M204V, S202K and M250I mutations.

Table 2 Distribution of amino acids substitution in reverse transcriptase region of Polymerase of HBV positive patients co-infected with HIV

\begin{tabular}{ll}
\hline Amino acids substitutions & Frequency \\
\hline Drug resistance associated & \\
M129L & $84 \%$ \\
M204V & $3 \%$ \\
L180M & $3 \%$
\end{tabular}




\begin{tabular}{ll} 
V163I & $78 \%$ \\
V173L & $3 \%$ \\
A223S & $16 \%$ \\
Compensatory mutation & \\
\hline Q125E & $13 \%$ \\
\hline S202K & $3 \%$ \\
\hline L217R & $21 \%$ \\
\hline V214A & $3 \%$ \\
\hline V204I & $3 \%$ \\
\hline I253Y & $50 \%$ \\
\hline T128A & $8 \%$ \\
\hline S105T & $40 \%$ \\
\hline
\end{tabular}

Table 3 Distribution of drug resistant mutations in reverse transcriptase region of Polymerase of HBV positive patients co-infected with HIV

\begin{tabular}{lllllll}
\hline Amino & Frequency & \multicolumn{5}{c}{ Drugs level of susceptibility } \\
\cline { 3 - 6 } Acids & $(\mathbf{n} / \mathbf{3 8})$ & & LMV & LdT & ETV & ADV \\
& & TDF & & & & \\
\hline M204V & 31 & Resistance & Resistance & Susceptible & Susceptible & Susceptible
\end{tabular}


L180M 1 Resistance Resistance Susceptible Susceptible Susceptible

\begin{tabular}{|c|c|c|c|c|c|c|}
\hline M129L & 1 & Unclear & Unclear & Unclear & Unclear & Unclear \\
\hline V163I & 1 & Resistance & Resistance & Susceptible & Susceptible & Susceptible \\
\hline
\end{tabular}

\begin{tabular}{|c|c|c|c|c|c|c|}
\hline $\begin{array}{l}\text { L180M } \\
\text { M204V }\end{array}$ & 1 & Resistance & Susceptible & Susceptible & Susceptible & Susceptible \\
\hline S202K & 1 & Resistance & Resistance & Resistance & Susceptible & Susceptible \\
\hline
\end{tabular}

\begin{tabular}{|c|c|c|c|c|c|c|}
\hline M250I & 1 & Susceptible & Susceptible & Susceptible & Resistance & Susceptible \\
\hline I223V & 1 & Susceptible & Susceptible & Susceptible & Resistance & Susceptible \\
\hline
\end{tabular}

I253Y

LMV- lamivudine; LdT- telbivudine; ETV- entecavir; ADV- adefovir; TDF-tenofovir

\section{Discussion}

In the current study, the HBsAg sero- prevalence in HIV-infected patients in Durban was $100 \%$. The HBsAg prevalence is higher than that from previous studies in South Africa ranging from $4.8 \%$ to $20 \%$ [15-17]. The HBsAg sero-prevalence from this cohort is not coherent with published data from Durban, in this region the reported HBsAg among HIV positive people ranges from $2.9 \%$ to $10 \%$ [18]. In this study HBsAg positive is a marker of active HBV infection in $100 \%$ HBsAg positive. However, the HBV DNA of the partial surface gene region was successfully amplified in 78 (41/50) individuals indicating that HBV DNA levels are not always associated with HBsAg levels because HBV DNA replication occur independent of HBsAg synthesis. The HBsAg and HBV DNA results from this study confirm the hyper endemic nature of HBV and HBV-HIV co-infection in South Africa. 
The phylogenetic analysis of the overlapping surface/polymerase gene covering nucleotides 256 to 796 from the EcoRI site of HBV in this study show the predominance of genotype A in the 38 individuals. This phylogenetic result is coherent with previous studies in South Africa [19-21]. The patients sequence were further identified as sub-genotype A1 by Geno2Pheno indicating that HBV significant diversity suggesting an African origin.

The surface antigen serves as an epitope to which the antibody attaches; hence it is used in current recombinant vaccines. The HBsAg contains the alpha $(\alpha)$, beta $(\beta)$ and T -cell epitopes, the " $\alpha$ " epitope is the main region targeted by antibodies and it contains the $(\beta)$ and T -cell epitopes [22]. The " $\alpha$ " epitope is referred to as the major hydrophilic region of HBsAg, which is between the amino acids $124-150$ region [23]. Amino acid substitution within the " $\alpha$ " epitope domain of HBsAg may cause structural and functional changes in the S protein [24].

We determined the mutations on the partial surface gene of HBV/HIV co-infected individuals from the Durban cohort. A total of 18 amino acid substitutions were observed within the HBsAg region in all 38 partial surface sequences. The sequences contained mutations at $\alpha, \beta$ and T-cell epitopes. There were four mutations (K122R, F134L, T143S and S117N) identified at the " $\alpha$ " epitope in the major hydrophilic region (aa79 to aa150) of the surface antigen. The " $\beta$ " epitope contained S207N, Y200T and G145R variants while in the "T" epitope P127T was identified. Mutations identified outside the " $\alpha$ " epitope mutations included E164D, L209V, Y206H, A194V, P70H, P127L, T189I, S204R and F129T. K122R and T143S mutations are reported to be associated with diagnostic failure [25]. Previous studies have failed to detect HBsAg in containing the K122R using certain ELISA diagnostic tests [26].

We identified seven vaccine escape mutations (P127T, G145R, S207N, Y200T, E164D, Y206H and L209V) identified in the HBsAg. The most common mutation was S207N, 
identified in 27 patients. P127T mutation was identified in 2 patients and has been reported to cause diagnostic escape within anti-HBc positive patients [27]. G145R was detected in 1 patient sequence and this mutation has previously been identified by [28, 29].G145R mutation is a major vaccine escape mutation in the " $\beta$ "-cell epitope of the " $\alpha$ " epitope of HBsAg, because it changes amino acid sequence of the " $\alpha$ " epitope structure hence it interferes with the antibody binding causing the HBsAg antigenicity to be reduced [30, 31].

G145R mutation is a classical mutation because it was the first vaccine-escape mutation identified from Italian vaccinated children [32]. Its occurrence has increased in recent years with an increase of HBV endemicity and use of universal immunization [22]. This mutation is crucial in causing failure on the detection of HBV by serological routine assays [25]. G145R has become more dominant with vaccine selection, and it is recommended to be incorporated into future vaccine design [28]. However, the prevalence of G145R and P127T mutants were low in this study, this might be linked to the incorporation of HBV vaccination into South African EPI in 2005 [33].

Another significant vaccine-escape mutation identified from this study was E164D. E164D was detected in 2 individuals; it was reported outside the "a" determinants epitopes. The E164D causes substitution change in the overlapping polymerase region creating the V173L mutation which is associated with lamivudine resistance therapy and causes the reduction of anti-HBs [34]. Mutation E164D causes substitutional change in the overlapping polymerase region creating the V173L mutation associated with lamivudine resistance therapy [34]. Other vaccine-escape mutations identified in this study were Y206H, L209V, S207N, Y200T and $\mathrm{P} 70 \mathrm{H}$ however, there is limited literature on their role in surface protein and HBV infection still needs to be explored. 
The HBV polymerase is the target of antiviral agents which are used to suppress the DNA replication of the HBV by blocking the reverse-transcription process. Antiviral agents used against HBV polymerase include the nucleoside/nucleotide analogues such as LMV, adefovir (ADV), TDF, telbivudine (LdT), and entecavir (ETV). In South Africa, lamivudine treatment is still the preferred treatment among the HBV/HIV co-infected patients, regardless of the introduction of TDF.

In addition, to the development of high mutation rate by the HBV error prone, antiviral drugs may also cause the development of drug resistance as a result of selection pressure during long-term use of the antiviral treatment [35]. The prevalence of mutations associated with drug resistance within the RT region 50\% (7/14). Drug resistance mutations included LMV resistance at $71 \%(5 / 7), \mathrm{LdT}$ at $57 \%(4 / 7), 14 \%$ (1/7) for ETF and 43\% (3/7) for ADV resistance. Mutations causing resistance to LMV were V173L, M204V, L180M, V163I, and S202K. Mutations associated with LdT resistance were M204V, L180M, V163I, and S202K; with S202K also being resistance to ETF. A combination of L180M and M204V gives crossresistance to other nucleosides and reduces sensitivity to ETV but not ADV and may cause vaccine escape mutations in the overlapping S-region and prevent the secretion of HBsAg [36]. ADV resistance mutations were I253Y, I223V and M250I.

Multiple drug resistance mutations within a single sample were identified from 1 patient containing L180M, M204V, S202K and M250I mutations. All the mutations associated with drug resistance identified in the polymerase (RT) were identified from genotype A sequences. Other compensatory mutations identified included S202K, Q125E, L217R, V124A, V204I, I253Y, T128A and S105T moreover. The effects on these mutations on the RT functions still 
need to be explored. The drug susceptibility prevalence was $65 \%$ (25/38). The drug susceptibility prevalence was $65 \%$ (25/38). There were mutations associated with resistance to tenofovir in this study, hence, we suggest tenofovir-based regimen in treatment of HBV in HBV/HIV co-infected individuals.

In this study, we identified mutations in the HBsAg region which are known to allow escape from neutralizing antibodies. These mutations in the HBsAg region may cause less reactivity with serological assays leading to failure in the detection of HBV by commercial enzymelinked immunosorbent assay (ELISA) assays. We also detected mutations within the polymerase and reverse transcriptase regions which are associated with antiviral drug resistance; hence mutations within this region may lead to treatment failure.

\section{Conclusion}

This study shows the predominance of HBV genotype A in HIV-infected patients and the HBV mutations present in HBV/HIV co-infected individuals. HBV mutations associated with drug resistance suggest the need for continuous HBV screening and use of tenofovir ART regimen among HBV/HIV co-infected individuals. In conclusion, this study has added to the limited South African data on HBV genotypes and mutations associated with pathogenesis and drug resistance in HBV/HIV co-infected individuals. We suggest that, the HIV samples be tested for mutations associated with drug resistance to compare the impact of drug resistance in the context of HIV/HVB co-infection. 


\section{List of abbreviations}

C: $\quad$ Degree Celsius $\mu \mathrm{l}$ :

Microlitre

uM: $\quad$ Micromolar

3TC: $\quad$ Lamivudine

ADV- $\quad$ Adefovir

Anti-HBc- Antibody to Hepatitis B core antigen

Anti-HBs- Antibody to Hepatitis B surface antigen

ART- $\quad$ Antiretroviral therapy DNA-

Deoxyribonucleic acid dNTP-

Deoxynucleoside triphosphate

DsDNA- Double-stranded DNA

ELISA- Enzyme-linked immunosorbent assay

EPI- $\quad$ Expanded Programme on Immunization

ETV- $\quad$ Entecavir

FTC- $\quad$ Emtricitabine

HBeAg- Hepatitis B e antigen

HBsAg- Hepatitis B surface antigen

HBV- Hepatitis B Virus

HCC- Hepatocellular carcinoma 
HIV- $\quad$ Human Immunodeficiency Virus

IgM- Immunoglobulin M

Ldt- Telbivudine ml-

Millilitre

PCR- Polymerase chain reaction

Pol- Polymerase rcDNA-

Relaxed circular DNA rpm-

Round per minute RNA-

Ribonucleic acid

RT- $\quad$ Reverse transcriptase ssRNA-

Single stranded RNA

TDF- Tenofovir disoproxil fulmarate

\section{Declarations}

\section{Ethics approval and consent to participate}

The study protocol and ethical certificate was approved by the North-West University Research Ethics Regulatory Committee (NWU-00068-15-A9). Written informed consent to participate in this study was obtained from all study participants prior to their recruitment. Written informed consent for publication was obtained from all study participants or their legal guardians prior to their recruitment. 


\section{Availability of data and material}

The sequences from this study have been deposited in GenBank under accession numbers KY827008-KY827014. The data and materials supporting this study finding are available and will be shared per request.

\section{Competing interests}

The authors of this study declare no competing interest.

\section{Funding}

This work was supported by funds from the North-West University, National Research foundation Innovation bursary, Health and Welfare Sector Education and Training Authority, South African Centre for Epidemiological Modelling and Analysis and Organisation for Women in Science for the Developing Worlds. These funding agencies were not involved and responsible in the study design and writing of the thesis and manuscript. The Authors in this study are solely responsible for the content and not the funding agencies involved.

\section{Authors' contributions}

Lorato Mosetsangape Modise (LMM) and Patricia Nomathamsanqa Sithebe (PNS) designed the study, LMM and PNS collected samples, LMM performed laboratory analyses on samples, LMM analysed the data and prepared the manuscript with participation from the other author. 


\section{Acknowledgements}

The authors would like to thank the National Health Laboratory Services in KwaZulu-Natal for donating samples for this study. We thank the State Key Lab of Virology, Wuhan Institute of Virology, Chinese Academy of Sciences for providing training on HBV genotyping and cell culturing. 


\section{References}

1. Summers J, O'Connell A, Millman I. Genome of hepatitis B virus: restriction enzyme cleavage and structure of DNA extracted from Dane particles. Proceedings of the National Academy of Sciences. 1975; 72(11): 4597-4601.

2. Musyoki AM, Kellogg T, Geibel S, Muraguri N, Okal J, Tun W, Raymond H, Dadabhai S, Sheehy M. Active co_infection with HBV and/or HCV in South African HIV positive patients due for cancer therapy. Journal of medical virology. 2015; 87(2): 213-221.

3. Gust ID, Burrell C, Coulepis A, Zuckerman A. Taxonomic classification of human hepatitis B virus. Intervirology. 1986; 25(1):14-29.

4. Liang TJ. Hepatitis B: the virus and disease. Hepatology. 2009; 49(S5).

5. Tatematsu K, Tanaka Y, Kurbanov F, Sugauchi F, Maeshiro T, Nakayoshi, TA. Genetic variant of hepatitis B virus divergent from known human and ape genotypes isolated from a Japanese patient and provisionally assigned to new genotype J. Journal of virology. 2009; 83(20):10538-10547.

6. Rahman MA, Hakim F, Ahsan C, Nessa J. Prevalence of genotypes and subtypes of hepatitis B viruses in Bangladeshi population. SpringerPlus. 2016; 5(1):78-80.

7. Audsley J, Littlejohn M, Yuen L, Sasadeusz J, Ayres A, Desmond C, Spelman T. HBV mutations in untreated HIV-HBV co-infection using genomic length sequencing. Virology. 2010; 405(2): 539-547.

8. Benson CA, Brooks J, Holmes K, Kaplan J, Masur H, Pau Alice. Guidelines for prevention and treatment opportunistic infections in HIV-infected adults and adolescents; recommendations from CDC, the National Institutes of Health, and the HIV Medicine Association/Infectious Diseases Society of America. Journal of virology. 2009; 59(2): 28-32. 
9. Di Martino V, Ezenfis J, Benhamou Y, Bernard B, Opolon P, Bricaire F, Poynard T. Severe acute pancreatitis related to the use of nelfinavir in HIV infection: report of a case with positive rechallenge. Aids. 1999; 13(11):1421.

10. Mphahlele M. Impact of HIV co-infection on hepatitis B prevention and control: a view from sub-Saharan Africa. Southern African Journal of Epidemiology and Infection. 2008; 23(1):14-18.

11. Kumar SK, Tamura, and Nei M. MEGA3: integrated software for molecular evolutionary genetics analysis and sequence alignment. Briefings in bioinformatics. 2004; 5(2):150-163.

12. Saitou N, Nei M. The neighbor-joining method: a new method for reconstructing phylogenetic trees. Molecular biology and evolution. 1987; 4(4):406-425.

13. Felsenstein J. Confidence limits on phylogenies: an approach using the bootstrap. Evolution. 1985; 39(4):783-791.

14. Kimura M. A simple method for estimating evolutionary rates of base substitutions through comparative studies of nucleotide sequences. Journal of molecular evolution. 1980; 16(2):111-120.

15. Firnhaber C, Viana R, Schultze D, Maskew M, Di Bisceglie A. Occult hepatitis B virus infection in patients with isolated core antibody and HIV co-infection in an urban clinic in Johannesburg, South Africa. International Journal of Infectious Diseases. 2009; 13(4): 488-492.

16. Cohen MS, Hellmann N, DeCock K, Lange J. The spread, treatment, and prevention of HIV-1: evolution of a global pandemic. The Journal of clinical investigation. 2008; 118(4):1244-1254. 
17. Hoffmann CJ, Charalambous S, Martin D, Churchyard G, Grant A, Fielding K. Hepatitis B virus infection and response to antiretroviral therapy (ART) in a South African ART program. Clinical Infectious Diseases. 2008; 47(11):1479-1485.

18. Amponsah_Dacosta E, Lebelo RJ. Burnett R, Selabe S. Evidence for a change in the epidemiology of hepatitis B virus infection after nearly two decades of universal hepatitis B vaccination in South Africa. Journal of medical virology. 2014;86(6):918924.

19. Kimbi, GC, Kramvis A, Kew MC, Distinctive sequence characteristics of subgenotype A1 isolates of hepatitis B virus from South Africa. Journal of general virology. 2004; 85(5):1211-1220.

20. Kramvis A. Genotypes and genetic variability of hepatitis B virus. Intervirology. 2014; 57(3-4):141-150.

21. Lukhwareni A, Burnett R, Selabe S, Mzileni MO, Mphahlele M. Increased detection of HBV DNA in HBsAg_positive and HBsAg_negative South African HIV/AIDS patients enrolling for highly active antiretroviral therapy at a Tertiary Hospital. Journal of Medical Virology. 2009; 81(3):406-412.

22. Caligiuri P, Cerruti R, Icardi G, Bruzzone B. Overview of hepatitis B virus mutations and their implications in the management of infection. World journal of gastroenterology. 2016; 22(1):145.

23. Liu J. Yan B, Feng Y, Song L, Zhang L. Comparison between two population-based hepatitis B serosurveys with an 8-year interval in Shandong Province, China. International Journal of Infectious Diseases. 2017; 61:3-19.

24. Zuckerman JN, Zuckerman AJ. Mutations of the surface protein of hepatitis B virus. Antiviral research. 2003; 60(2):55-78.

25. Cooreman MP, Leroux-Roels G, Paulij WP. Vaccine-and hepatitis B immune 
globulin-induced escape mutations of hepatitis B virus surface antigen. Journal of biomedical science. 2001; 8(3):237-247.

26. Malik A, Singhal D, Albanyan A, Husain S. Hepatitis B virus gene mutations in liver diseases: a report from New Delhi. PloS one. 2012;7(6):39028.

27. Kuzin S, Zabotina E, Kudriavtseva E, Samokhvalov EI, Borisova OV. Heterogeneity of hepatitis B virus and diagnostic potential of modern test systems for the detection of HBsAg. Zhurnal mikrobiologii, epidemiologii, i immunobiologii. 2012; (1):68-75.

28. Yan B, Zhong G, Xu G, Jing Z. Temporal trend of hepatitis B surface mutations in the post-immunization period: 9 years of surveillance (2005-2013) in eastern China. Scientific reports. 2017; 7(1):6669.

29. Colson P, Borentain P, Motte A, Moal V, Botta-Fridlund D. Clinical and virological significance of the co-existence of $\mathrm{HBsAg}$ and anti-HBs antibodies in hepatitis B chronic carriers. Virology. 2007; 367(1):30-40.

30. Su IJ. Ground glass hepatocytes contain pre_S mutants and represent preneoplastic lesions in chronic hepatitis B virus infection. Journal of gastroenterology and hepatology. 2008; 23(8):1169-1174.

31. Kao JH, Chen DS. Global control of hepatitis B virus infection. The Lancet infectious diseases. 2002; 2(7):395-403.

32. Zanetti A, Tanzi E, Manzillo G, Sbreglia C, Caporaso N. Hepatitis B variant in Europe. Lancet. 1988; 2(8620):1132-3.

33. Magoro T, Gachara G, Mavhandu L, Lum E, Kimbi H, Ndip RN, Bessong P. Serologic markers and molecular pidemiology of HBV in an HIV infected cohort from Cameroon. Virology Journal. 2016; (13):178. 
34. Torresi J. The virological and clinical significance of mutations in the overlapping envelope and polymerase genes of hepatitis B virus. Journal of clinical virology, 2002; 25(2):97-106.

35. Fares MA, Holmes EC. A revised evolutionary history of hepatitis B virus (HBV). Journal of molecular evolution. 2002; 54(6): 807-814.

36. Sheldon J, Camino N, Rodés B, Bartholomeusz A, Kuiper M, Núñez M, Mauss S, Lutz T, Klausen G. Selection of hepatitis B virus polymerase mutations in HIVcoinfected patients treated with tenofovir. Antiviral therapy. 2005; 10(6):727.

Figure 1 Amplified overlapping surface/polymerase region HBV. Genome position (256 to 796 EcoRI site) shown as 547 bp amplicons on a $1 \%$ ethidium bromides-stained agarose gel obtained from the HIV infected KZN cohort. M (first well) = 1000 plus bp molecular weight marker Well 2 (lane 1, lane 2 and lane 3)= positive control Well 3 to well 19 (lane 1, lane 2 and lane 3) = partial surface region amplicons of targeted band size $\sim 547 \mathrm{bp}$

Figure 2 Phylogenetic tree comparing the $S$ gene sequences of this study. Representative sequences obtained from the GenBank (designated by accession numbers). Study sequences *are represented by letters Q. 


\section{Figures}

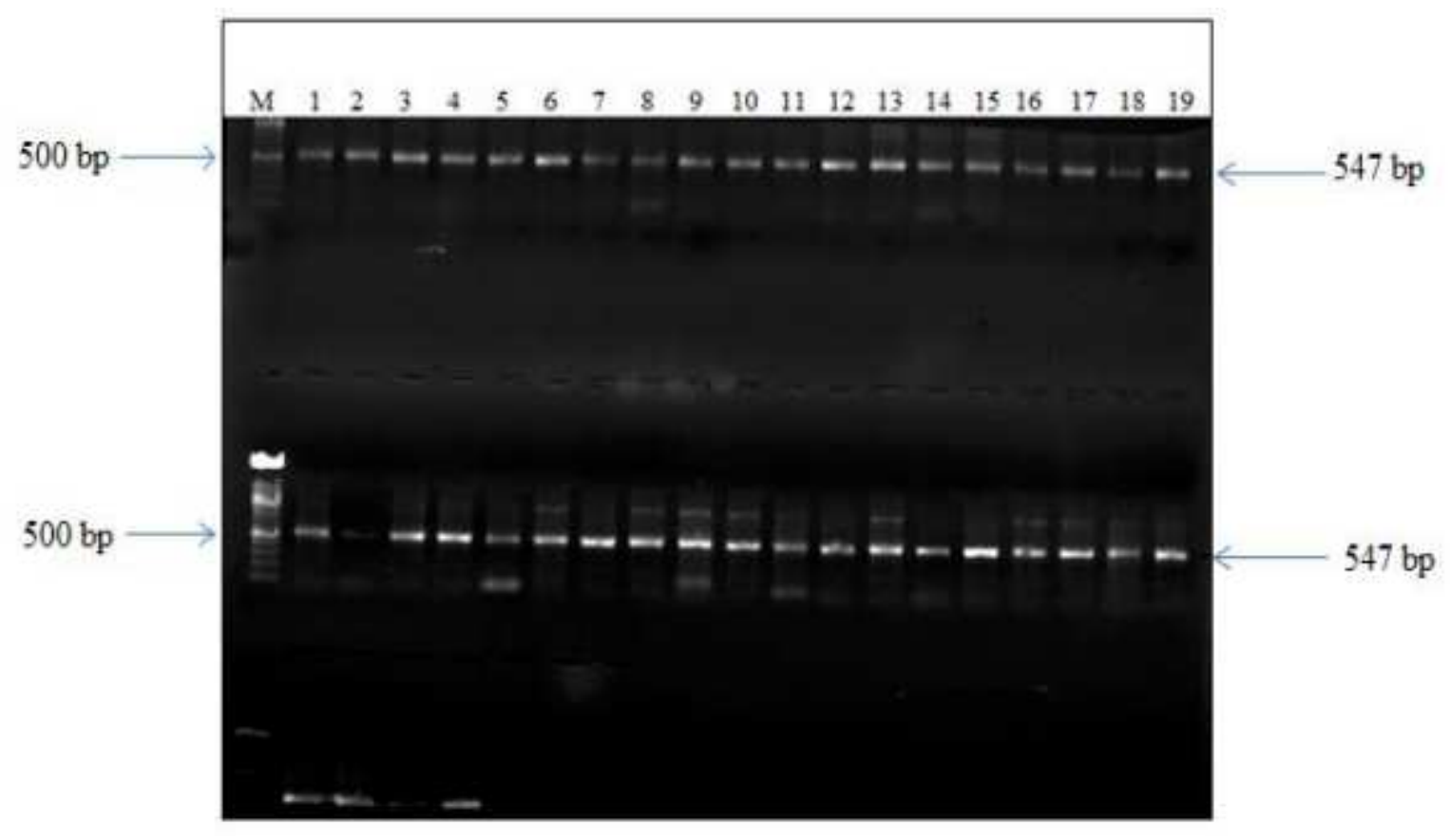

\section{Figure 1}

Amplified overlapping surface/polymerase region HBV. Genome position (256 to 796 EcoRI site) shown as $547 \mathrm{bp}$ amplicons on a $1 \%$ ethidium bromides-stained agarose gel obtained from the HIV infected KZN cohort. $\mathrm{M}$ (first well) $=1000$ plus bp molecular weight marker Well 2 (lane 1, lane 2 and lane 3 ) = positive control Well 3 to well 19 (lane 1, lane 2 and lane 3 ) = partial surface region amplicons of targeted band size $~ 547 \mathrm{bp}$ 


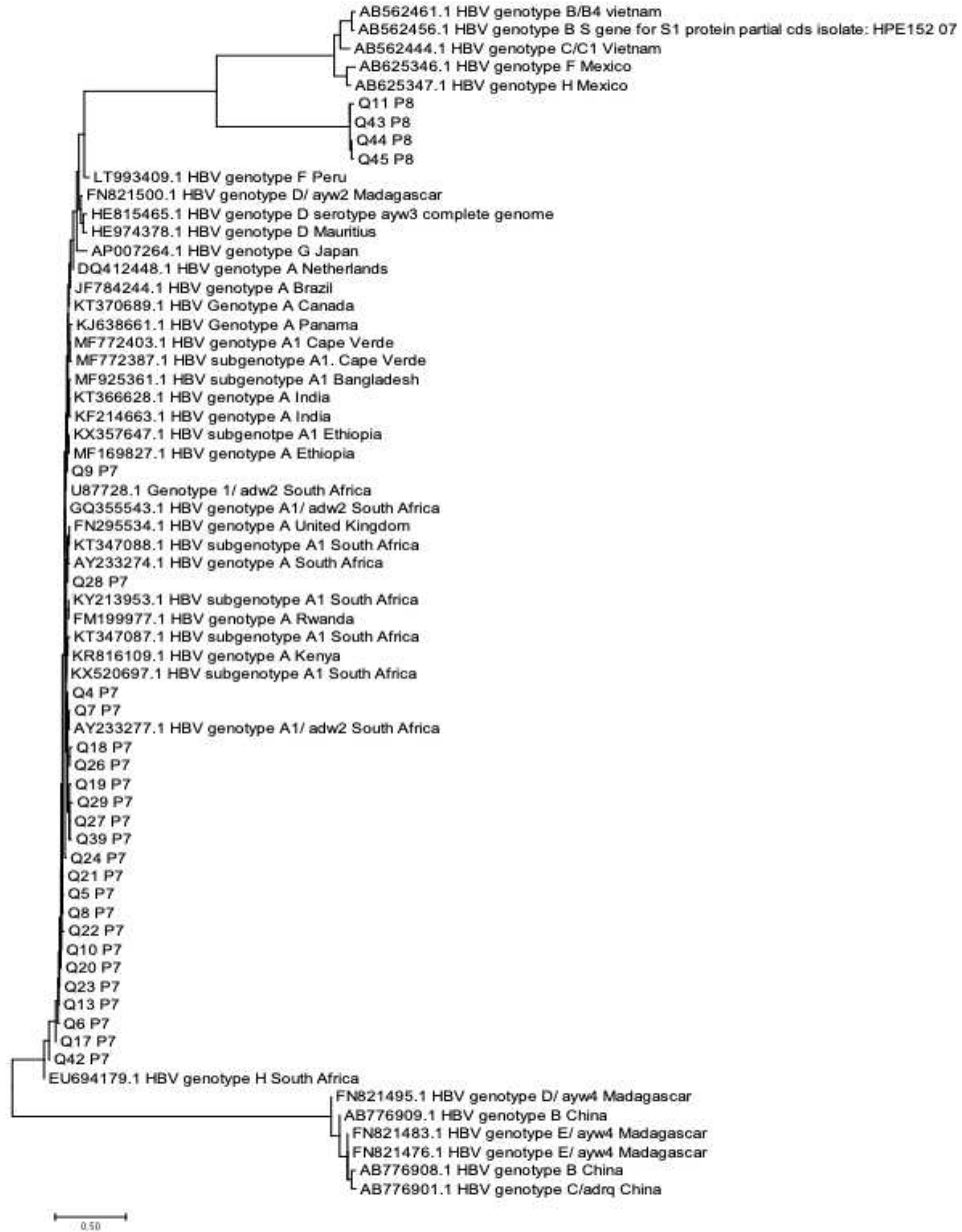

\section{Figure 2}

Phylogenetic tree comparing the $S$ gene sequences of this study. Representative sequences obtained from the GenBank (designated by accession numbers). Study sequences *are represented by letters Q. 